Article

\title{
Synthesis and Characterization of Crystalline NaY-Zeolite from Belitung Kaolin as Catalyst for n-Hexadecane Cracking
}

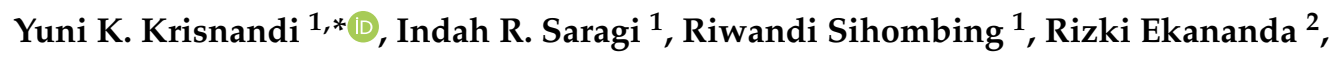 \\ Indah P. Sari ${ }^{1}$, Benjamin E. Griffith ${ }^{3}$ and John V. Hanna ${ }^{3}(\mathbb{D}$ \\ 1 Department of Chemistry, Faculty of Mathematics and Natural Science, Universitas Indonesia, Depok 16424, \\ Indonesia \\ 2 Pertamina Research and Technology Center, Jl. Raya Bekasi No 20, Jakarta 13920, Indonesia \\ 3 Department of Physics, University of Warwick, Coventry CV4 7AL, UK \\ * Correspondence: yuni.krisnandi@sci.ui.a.id
}

Received: 30 June 2019; Accepted: 1 August 2019; Published: 4 August 2019

check for updates

\begin{abstract}
Crystalline sodium Y (NaY) zeolite has been synthesized using alternative natural source of aluminate and silicate, extracted from natural Belitung kaolin. Prior to use, the natural kaolin was pretreated to obtain fragmented metakaolin and extracted silica. Synthesis was conducted with the addition of $\mathrm{NaY}$ gel (two types of NaY seeds were used, prepared from colloidal sillica or sodium silica water) using hydrothermal method for $21 \mathrm{~h}$ at $100^{\circ} \mathrm{C}$. The characterization on the as-synthesized zeolites confirmed that the one prepared using colloidal silica-seed has closer structure similarity to $\mathrm{NaY}$ zeolite that was synthesized using pro analysis silicate and aluminate sources. Thus, the rest of the synthesis of $\mathrm{NaY}$ was carried out using colloidal silica-NaY seed. The NaY zeolites then were converted to HY, through ammonium-exchange followed by calcination, to be tested as cracking catalysts using $n$-hexadecane as a probe molecule. It shows that HY from metakaolin and extracted silica gives high performance, i.e., $n$-hexadecane conversion of $58 \%-64 \%$, also $C_{5}-C_{12}$ percentage yield and selectivity of $56 \%-62 \%$ and $98 \%$. This work has shown the potential to utilize kaolin as alternative silicate aluminate sources for crystalline zeolite synthesis and to obtain inexpensive and environmentally friendly catalyst materials.
\end{abstract}

Keywords: natural aluminosilicate; kaolin; metakaolin; extracted silica; zeolite Y; n-hexadecane cracking

\section{Introduction}

Zeolite, one type of tectosilicate group from alumina silicate family [1,2], has played an important role for more than 100 years in the chemical industry, and is widely used in various fields such as water purification [3,4], adsorption, separation, anticorrosion [5] and catalysis processes [6]. Furthermore, Zeolite Y, a member of Faujasite (FAU) framework has long been used as a catalyst in cracking reaction for crude petroleum to more valuable gasoline, diesel and many products [7]. Its superiority properties such as unique topology, large surface area, adsorption capacity, pore size uniformity, thermal stability and having active sites with diverse strength become the main attractions related to their application [8].

Conventional hydrothermal zeolite synthesis method is still quite popular. The synthesis is carried out by mixing certain amount of aluminate $\left[\mathrm{AlO}_{4}\right]^{5-}$ and silicate $\left[\mathrm{SiO}_{4}\right]^{4-}$ precursors in an alkaline medium at $60-200{ }^{\circ} \mathrm{C}$ in Teflon-lined autoclave for a specific time [9]. However, synthesis of high crystalline zeolite is still expensive because it requires pro analytical chemicals as precursors of aluminate and silicate. On the other hand, in some countries including Indonesia, natural aluminosilicate 
mineral deposits are abundant which provide a potential replacement for pro analytical silicate and aluminate precursor. Therefore, the raw materials for zeolite synthesis become inexpensive and more environmentally friendly which aligned with the "Green Chemistry" concept [10]. Some materials have also been used as an alternative, including fly ash, rice husk and kaolin [11]. Kaolin is a member of phyllosilicate or clay group, comprised of layers of aluminates and silicates that consists of $\mathrm{Al}$ in octahedral coordination with $\mathrm{OH}$ which bound to one sheet of $\mathrm{Si}$ in tetrahedral coordination with $\mathrm{O}$ [12]. In fact, kaolin and halloysite, another member of phyllosilicate group, have already been studied as hybrid materials and used as catalysts [13-15].

In our work, we utilized kaolin as alumina and silica sources by destroying their original structure and transforming to completely different structure of materials, zeolite from tectosilicate group. However, in our previous synthesis, synthetic aluminate or silicate sources, not including seed, are still being added. For example, synthetic precursors have been added in the synthesis of $\mathrm{NaY}$ and ZSM-5 [16-18]. In this work, the synthesis of NaY from Indonesian kaolin as raw materials for precursors using seeding method has been carried out without the addition of synthetic precursors for aluminates and silicates. Preliminary work on this has been reported in [19]. Afterwards, it was transformed to HY and employed as a catalyst for cracking $n$-hexadecane as a model molecule. The characterization results indicate the synthesis was successful, and the modified HY zeolites has high activity as cracking catalysts towards $n$-hexadecane.

\section{Materials and Methods}

\subsection{Chemicals}

Indonesian kaolin from Belitung island was provided by PT. Aneka Kaoline Utama (Belitung Island, Indonesia)and colloidal silica Ludox HS 40 and $n$-hexadecane were purchased from Sigma Aldrich (St.Louis, Missouri, US). Acetic glacial acid, sodium acetate trihydrate, hydrogen peroxide $(30 \%)$, nitric acid, hydrochloric acid, sodium hydroxide (pellet, 99\%), trisodium citrate dihydrate and sodium bicarbonate were procured from Merck (Darmstadt, Germany). Commercial NaY was purchased from Wako (Chuo-Ku, Osaka, Japan) and directly used as comparison.

\subsection{Pre-Treatment of Natural Kaolin}

Prior use, Belitung natural kaolin was sieved until it reached a size of $\leq 100 \mu \mathrm{m}$ and then subjected to physical activation, purification and calcination [20]. Activation was performed by dispersing the kaolin with deionized water $(1: 3 \mathrm{w} / \mathrm{v})$ under vigorous stirring for $3 \mathrm{~h}$ at room temperature, then filtered and dried at $105^{\circ} \mathrm{C}$. Purification was conducted by dispersing activated kaolin in solution with $\mathrm{pH} 5$ (adjust with $1 \mathrm{M}$ sodium acetate) and mixture of $30 \% \mathrm{H}_{2} \mathrm{O}_{2}$ : Dithionite-citrate-bicarbonate $(1: 10 \mathrm{v} / \mathrm{v})$, filtered and dried at $100{ }^{\circ} \mathrm{C}$. Then, the purified kaolin was heated up to $800{ }^{\circ} \mathrm{C}-1000{ }^{\circ} \mathrm{C}$ to obtain meta-kaolin [21]. Silica extraction was carried out by dissolving some amount of meta-kaolin in aqua regia $\left(\mathrm{HCl}: \mathrm{HNO}_{3}\right.$ with a ratio of $\left.3: 1(\mathrm{v} / \mathrm{v})\right)$ for $4 \mathrm{~h}$ at $100{ }^{\circ} \mathrm{C}$. After this process, the extracted silica was collected and washed using deionized water until its $\mathrm{pH}$ reached neutral.

\subsection{Synthesis of NaY Zeolite}

Synthesis of $\mathrm{NaY}$ zeolite was carried out according to certain molar composition $\left(\mathrm{Na}_{2} \mathrm{O}: \mathrm{Al}_{2} \mathrm{O}_{3}\right.$ : $\mathrm{SiO}_{2}: \mathrm{H}_{2} \mathrm{O}=10.67: 1: 10: 180$ ) as reported in Liu, 2016 [22] with some adjustment. Certain amount of metakaolin and extracted silica were used as aluminate and silicate source accordingly, based on the $\mathrm{SiO}_{2} / \mathrm{Al}_{2} \mathrm{O}_{3}$ ratio of the pretreated materials. They were mixed with deionized water until homogeneous. Two sets of NaY seeds were prepared using colloidal silica (Ludox HS40) or sodium silica water by following the molar ratio reported in Ginter, et al. [23]. Then, the seed $10 w / w \%$ of the mixture was transferred to the mixture, was stirred in propylene bottle and aged for $24 \mathrm{~h}$ at room temperature. The crystallization was carried out in Teflon-lined stainless-steel autoclave and 
polypropylene bottle at $100^{\circ} \mathrm{C}$ for $24 \mathrm{~h}$. The white precipitate then was filtered, washed and dried at room temperature.

\subsection{Characterization}

Extensive solid-state characterization techniques such as X-Ray Diffraction (XRD), X-Ray Fluoresence (XRF), Fourier Transform-Infra Red (FTIR), Scanning Electron Microscopy with Energy Dispersive X-Ray Spectroscopy (SEM-EDX), were carried out on kaolin, metakaolin, extracted silica and the as-synthesized material. Analysis of functional group of $\mathrm{NaY}$ zeolite was carried out using Alpha Bruker FTIR spectrometer. XRD analysis was carried out on PANanalytical: X'Pert Pro XRD Elemental analysis was performed on PANanalytical: Epsilon1 X-Ray Flourosence Spectrometer (XRF) (Complete surface area analysis was characterized using Quantachrome. All the characterization were carried out at Universitas Indonesia. SEM Image was captured at KAIST, South Korea, using Field Emission SEM FEI Magellan 400 and FIG Quanta FEG 450.

All solid state NMR measurement were conducted at the University of Warwick's Solid State NMR facility, UK. All ${ }^{29}$ Si single pulse Magic-Angle Spinning Nuclear Magnetic Resonance (MAS NMR) measurements were performed at $7.05 \mathrm{~T}\left({ }^{29} \mathrm{Si}\right.$ Larmor frequency $\left(v_{\mathrm{o}}\right)$ of $59.6 \mathrm{MHz},{ }^{1} \mathrm{H}$ Larmor frequency of 300.1 MHz) using a Varian/Chemagnetics Infinity Plus spectrometer. These experiments were performed using a Bruker $7 \mathrm{~mm} \mathrm{HX}$ probe which enabled a MAS frequency of $5 \mathrm{kHz}$ to be implemented. Pulse length calibration was performed on solid kaolinite from which a ${ }^{29} \mathrm{Si} \pi / 2$ pulse time of $4.25 \mu$ s was measured. All experiments were undertaken using a ${ }^{29} \mathrm{Si} \pi / 2 \mathrm{flip}$ angle, a recycle delay of $240 \mathrm{~s}$, and high power ${ }^{1} \mathrm{H}$ decoupling of $80 \mathrm{kHz}$ during data acquisition. The analogous cross-polarization MAS (CPMAS) experiments utilized an initial ${ }^{1} \mathrm{H} \pi / 2$ pulse of $4 \mu \mathrm{s}$, a Hartmann-Hahn contact time of $4 \mathrm{~ms}$ which was comprised of a ramp from $75 \%$ and $100 \%$ during that period, a $2.5 \mathrm{~s}$ recycle delay, and high power ${ }^{1} \mathrm{H}$ decoupling of $80 \mathrm{kHz}$ during data acquisition. All ${ }^{29} \mathrm{Si}$ chemical shifts were reported against the IUPAC recommended primary reference of $\mathrm{Me}_{4} \mathrm{Si}\left(\delta_{\text {iso }}=0.0 \mathrm{ppm}\right)$, via a kaolinite secondary reference at $\delta_{\text {iso }}=-92 \mathrm{ppm}$ [24].

Single pulse ${ }^{27} \mathrm{Al}$ MAS NMR measurements were performed at $9.45 \mathrm{~T}\left({ }^{27} \mathrm{Al}\right.$ Larmor frequency of 103.9 MHz) using a Bruker Avance HD-400 spectrometer. All experiments were conducted using a Bruker $3.2 \mathrm{~mm}$ HX probe which enabled a MAS frequency of $20 \mathrm{kHz}$. The ${ }^{27} \mathrm{Al}$ pulse optimization and chemical shift referencing was undertaken using the IUPAC primary reference of $1.1 \mathrm{M}$ solution of $\mathrm{Al}\left(\mathrm{NO}_{3}\right)_{3}$ set to $0 \mathrm{ppm}$ [1]. A 'non-selective' (solution) $\pi / 2$ pulse time of $18 \mu \mathrm{s}$ (corresponding to a 'selective' (solid) pulse time of $6 \mu \mathrm{s}$ ) was accurately calibrated on this solution. In order to obtain quantitative results, a tip angle of $\pi / 12$ was used which corresponded to a selective $1.0 \mu$ s pulse length which was used with a recycle delay of $0.5 \mathrm{~s}$.

\subsection{Catalytic Cracking Test}

The catalytic activity of HY zeolites was tested using micro activity test (MAT) reactor located at PT Pertamina, following procedure reported in [18]. Approximately $0.5 \mathrm{~g}$ of catalyst was placed into a silica reactor, purged with $\mathrm{N}_{2}$ gas to remove all impurities at a temperature of $573 \mathrm{~K}$ for $30 \mathrm{~min}$, followed by injection of $1.35 \mathrm{~g}$ of $n$-hexadecane feed into the reactor for $80 \mathrm{~s}$. After the reaction finished, the gas and liquid products were collected and characterized with GC-RGA and GC simulated distillation, respectively.

\section{Results}

\subsection{Characterization of Raw Materials}

The detailed composition and $\mathrm{SiO}_{2} / \mathrm{Al}_{2} \mathrm{O}_{3}$ ratio from Belitung kaolin is measured using $\mathrm{XRF}$, before and after pre-treatment, is listed in Table 1. It reveals that in raw kaolin, $\mathrm{SiO}_{2}$ and $\mathrm{Al}_{2} \mathrm{O}_{3}$ were the predominant oxides with a mass ratio of 1.71. The $\mathrm{SiO}_{2} / \mathrm{Al}_{2} \mathrm{O}_{3}$ ratio of metakaolin, as a result of dehydroxilation process to kaolin, is not different from that of kaolin. However while silica extraction 
has successfully removed $88 \%$ of aluminate $\left(\mathrm{AlO}_{4}{ }^{5-}\right)$ and increased the silicate $\left(\mathrm{SiO}_{4}\right)$ content to $90.5 \%$. The metakaolin and extracted silica then were used as precursors in $\mathrm{NaY}$ synthesis.

Table 1. Composition of the raw kaolin, metakaolin and extracted silica precursors.

\begin{tabular}{cccc}
\hline Chemical Composition & \%-Mass Kaolin & \%-Mass Metakaolin & \%-Mass Extracted Silica \\
\hline $\mathrm{Na}_{\mathbf{2}} \mathbf{O} / \mathbf{K}_{\mathbf{2}} \mathbf{O}$ & 4.48 & 5.31 & 1.353 \\
$\mathbf{A l}_{\mathbf{2}} \mathbf{O}_{\mathbf{3}}$ & 33.39 & 33.39 & 3.952 \\
$\mathrm{SiO}_{\mathbf{2}}$ & 57.11 & 56.70 & 90.487 \\
$\mathbf{C l}$ & 0.59 & 0.53 & 0.581 \\
$\mathrm{CaO}$ & 0.68 & 0.59 & 0.513 \\
$\mathbf{F e}_{\mathbf{2}} \mathbf{O}_{\mathbf{3}}$ & 3.75 & 3.57 & 1.567 \\
$\mathbf{S i O}_{\mathbf{2}} / \mathbf{A l}_{\mathbf{2}} \mathbf{O}_{\mathbf{3}}$ & 1.71 & 1.69 & 22.89 \\
\hline
\end{tabular}

XRD patterns of starting materials (Figure 1) shows that the structure of raw kaolin stays intact after purification, but then changed significantly after dehydroxylation processes to form metakaolin. The absence of kaolinite peaks at $2 \theta 12.36^{\circ}$ and $24.88^{\circ}$ indicates that the long-ordered pattern of layered aluminosilicate no longer existed due to dehydroxylation process, damaging bonding amongst silicate/aluminate in the structure. Further change is shown in the pattern of extracted silica, in which most of the peaks related to kaolinite structure [25], leaving the broad hump around $2 \theta 15^{\circ}-35^{\circ}$, indicative of materials that became more amorphous.

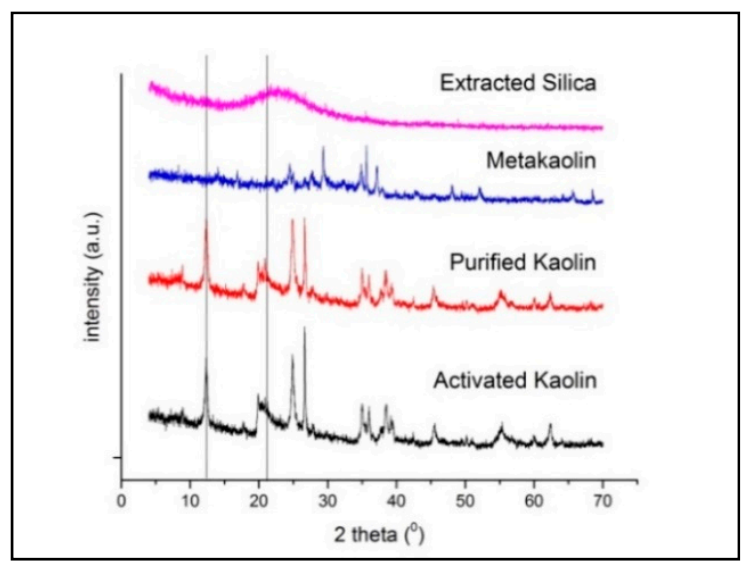

Figure 1. X-Ray Diffraction data for the raw precursor materials.

FTIR spectra from Figure 2 shows that the spectra of raw materials, activated and purified kaolin had similar peaks. There were two sharp peaks between $3700 \mathrm{~cm}^{-1}$ and $3614 \mathrm{~cm}^{-1}$ assigned for stretching structural hydroxyl groups $(-v \sim \mathrm{Si}-\mathrm{OH}$ and $\sim \mathrm{Al}-\mathrm{OH}$ respectively), typical from phyllosilicate aluminosilicates [26]. The $1650 \mathrm{~cm}^{-1}-1600 \mathrm{~cm}^{-1}$ band, attributed to adsorbed water molecule bending vibration (H-O-H), is observed. A group of large bands at $1121 \mathrm{~cm}^{-1}-1019 \mathrm{~cm}^{-1}$, attributed to Si-O-Si(Al) asymmetric stretching vibration groups, $922 \mathrm{~cm}^{-1}$ for Al-OH groups, $785 \mathrm{~cm}^{-1}-698 \mathrm{~cm}^{-1}$ for Si-O-Al groups and $1400 \mathrm{~cm}^{-1}-420 \mathrm{~cm}^{-1}$ for Si-O covalent bond were observed. After dehydroxylation process, the two peaks attributed to $\sim \mathrm{Si}-\mathrm{OH}$ and $\sim \mathrm{Al}-\mathrm{OH}$ bands merged into one broad band at $3750 \mathrm{~cm}^{-1}-3500 \mathrm{~cm}^{-1}$. A group of new peaks observed at $1500-1350 \mathrm{~cm}^{-1}$ attributed to Al-O-Al [27], separated from original Al-O-Si bonds appeared at $1121 \mathrm{~cm}^{-1}-1019 \mathrm{~cm}^{-1}$. This result is in agreement with disruptive $\sim \mathrm{Al}-\mathrm{O}-\mathrm{Si} \sim$ after kaolin transformed to metakaolin [25]. Extracted silica also show different spectra from kaolin and metakaolin. It can be seen that the spectrum of extracted silica has broad peak for hydrogen bonded $\sim \mathrm{Si}-\mathrm{OH}$ group at $3700-3490 \mathrm{~cm}^{-1}$, a peak attributed to adsorbed water molecule at $1620 \mathrm{~cm}^{-1}$ and broad peak at $1200-1000 \mathrm{~cm}^{-1}$ assigned for Si-O groups, while the peaks for $\sim$ Al-O groups disappeared. This is indicative of aluminum removal, supporting the XRD and XRF data and successful silica extraction. 


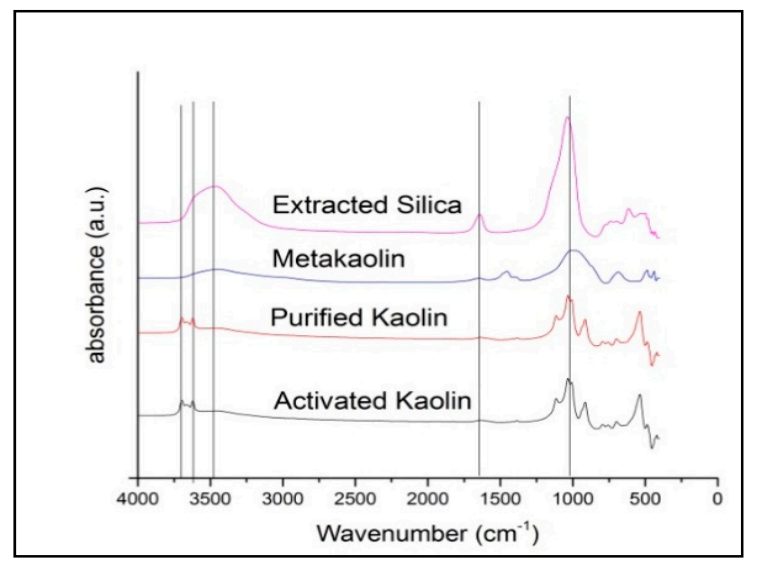

Figure 2. Fourier Transform-Infra Red spectra for the raw precursor materials.

SEM Images in Figure 3a displays the layered structure of kaolin, as a member of phyllosilicate group [12,26]. Meanwhile the metakaolin image in Figure 3b shows that the structure has been damaged and become amorphous after dehydroxylation. This is in agreement with the results reported in Abdullahi, et al. [28].
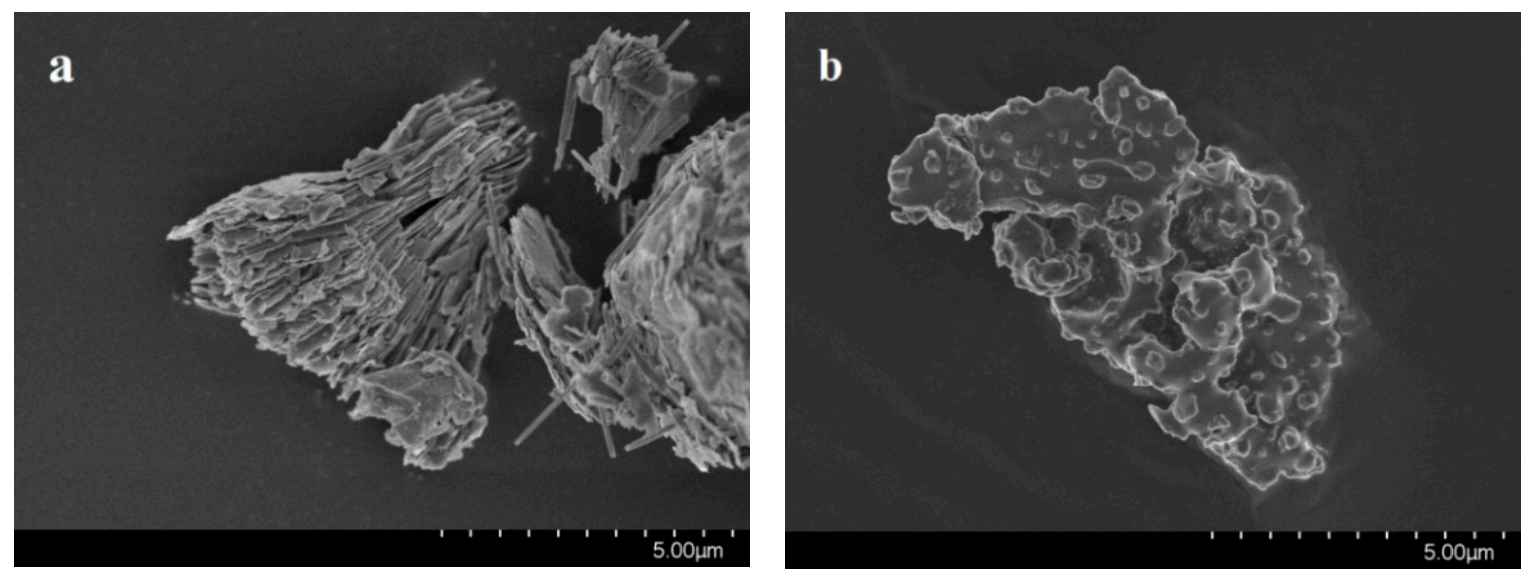

Figure 3. Scanning Electron Microscopy images for (a) kaolin and (b) metakaolin.

${ }^{29} \mathrm{Si}$ and ${ }^{27} \mathrm{Al}$ solid state NMR measurements from Figure 4 were carried out to obtain more information on structural changes on kaolin before and after pre-treatment. Figure 4a shows the NMR spectra of raw kaolin. The ${ }^{29} \mathrm{Si}$ NMR spectra consists of a single peak at $-90 \mathrm{ppm}$ that attributed to $\mathrm{Q}^{3}$-Si tetrahedral with three bridges oxygen atom and one non bridge oxygen atom $(3 \mathrm{Si}, 1 \mathrm{Al})$, according to Stepanov, et al., 2016 [29], while the ${ }^{27} \mathrm{Al}$ NMR shows a single peak at $0 \mathrm{ppm}$ which ascribed to octahedral $\mathrm{Al}$ [29]. This agrees to the structure of tetrahedral $\left(\mathrm{SiO}_{4}\right)$-octahedral $\left(\mathrm{AlO}_{6}\right)$-tetrahedral $\left(\mathrm{SiO}_{4}\right)$ layers in raw kaolin. In metakaolin, as shown in Figure $4 \mathrm{~b}$, most of $\mathrm{Si}$ peak is still $\mathrm{Q}^{3}$ but with poorer environment, but the $\mathrm{Al}$ peak is shifted to $-60 \mathrm{ppm}$, which attributed to $\mathrm{AlO}_{4}$, the tetrahedral $\mathrm{Al}$ [30]. This indicates that after dehydroxylation, the layered structure of kaolin is fragmented to $\mathrm{SiO}_{4}$ and $\mathrm{AlO}_{4}$. Overall, from all the characterization results, the silicate and aluminate precursors for synthesis of $\mathrm{NaY}$ have successfully been provided. 

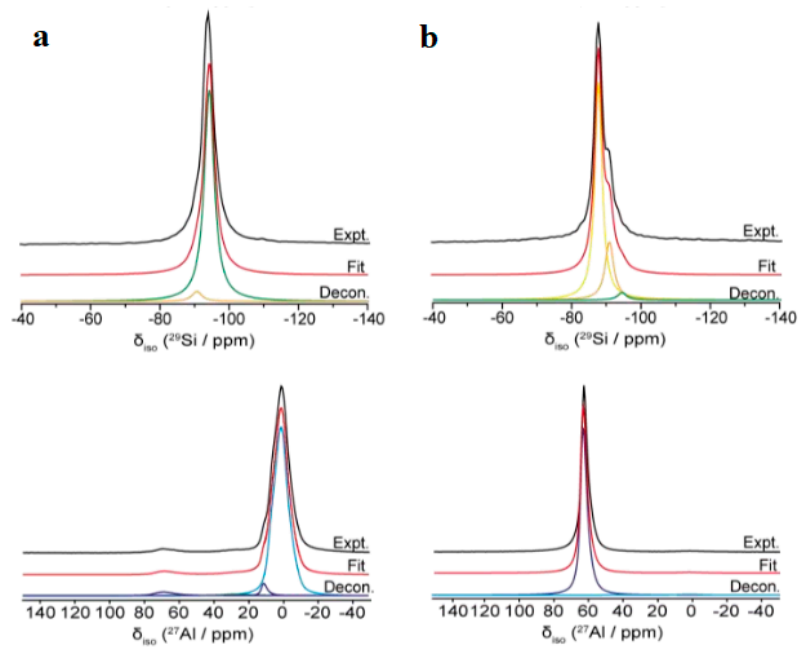

Figure 4. ${ }^{29}$ Si Magic-Angle Spinning Nuclear Magnetic Resonance data (top) and ${ }^{27}$ Al MAS NMR data (bottom) spectra of (a) raw kaolin and (b) metakaolin.

\subsection{Synthesis of NaY Zeolite Seeds}

The NaY seeds were prepared following the method reported by Liu, et al. [22] using two types of silicate sources, LUDOX HS40 and silica water, and compared to commercial NaY from Wako. The characterization results of the $\mathrm{NaY}$ seeds are explained below.

XRD pattern from Figure 5 shows the XRD patterns of NaY zeolites synthesis using LUDOX HS-40 and silica water as silicate sources, labeled NaY-LDX and NaY-SW respectively. They were compared to the pattern of NaY from Abbas, et al. [31] and Foster, et al. from IZA Online [32]. From this figure, it reveals that only NaY-LDX has typical peaks of NaY zeolite and has a similarity with $\mathrm{NaY}$ zeolite commercial. Thus, it was chosen as seed for the rest of NaY synthesis.

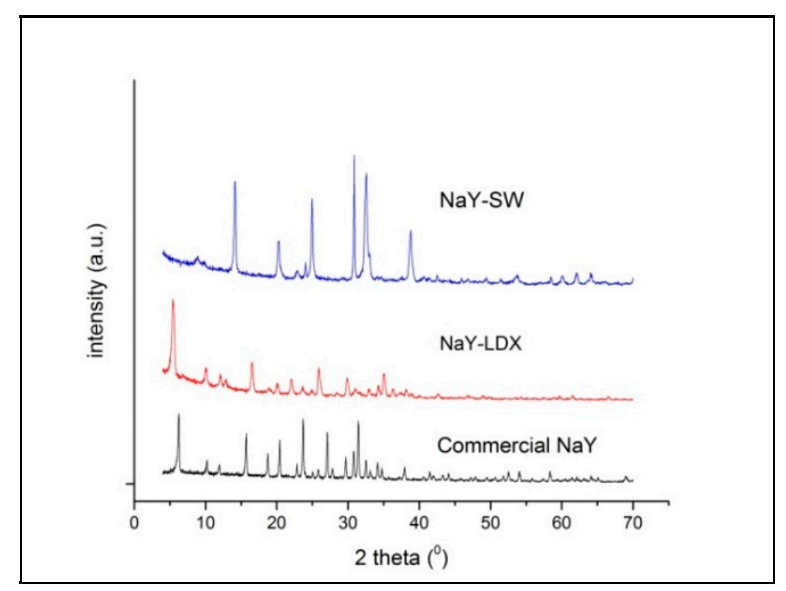

Figure 5. XRD data of as-synthesized NaY seeds synthesized using silica water (top) and LUDOX (middle) compared with commercial NaY (bottom).

Figure 6 presents the infrared spectra of as-synthesized and commercial NaY zeolites. The broad band between $3650 \mathrm{~cm}^{-1}$ and $3405 \mathrm{~cm}^{-1}$ is attributed to the hydrogen-bonded silanol groups from the surface of zeolites, while peak at $1640 \mathrm{~cm}^{-1}$ indicates the existence of water molecule on the surface. The large peak at $1140-450 \mathrm{~cm}^{-1}$ is assigned for the lattice $\mathrm{Si}-\mathrm{O}-\mathrm{Si}$ or $\mathrm{Si}-\mathrm{O}-\mathrm{Al}$ vibrations. The peaks observed at finger print area below $700 \mathrm{~cm}^{-1}$ are similar to that of the typical peaks from $\mathrm{NaY}$ [26]. 


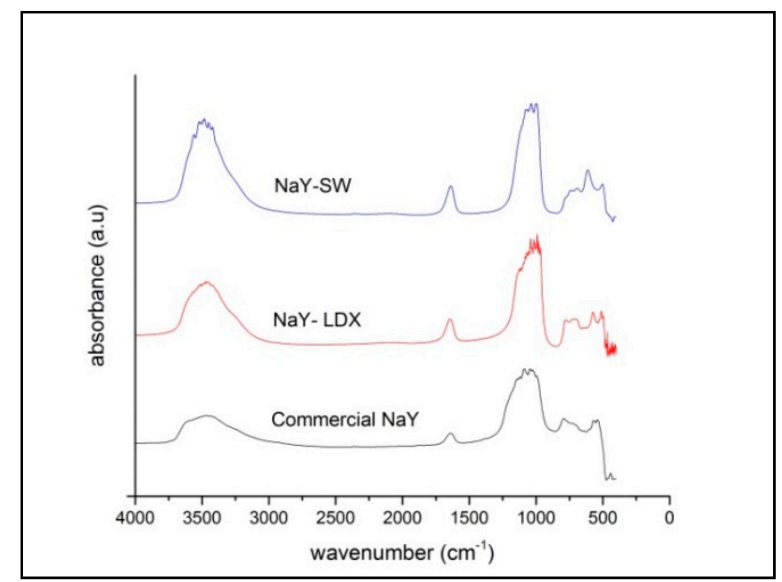

Figure 6. FTIR spectra of as-synthesized of $\mathrm{NaY}$ zeolite using $\mathrm{NaY}$ seeds generated from silica water (top) and LUDOX (middle), compared to commercial NaY (bottom).

The ${ }^{29} \mathrm{Si}$ and ${ }^{27} \mathrm{Al}$ solid state NMR from Figure 7 are very powerful probes to analyze the structure of $\mathrm{Si}$ and $\mathrm{Al}$ species in the aluminosilicate materials [29]. Figure 7 shows the ${ }^{29} \mathrm{Si} \mathrm{NMR}$ spectra of the NaY-LDX, NaY-SW and commercial NaY zeolites. It can be seen from the results of the deconvolution of each material that there are five peaks at chemical shifts of -80 to $-90 \mathrm{ppm},-85$ to $-95 \mathrm{ppm},-90$ to $-100 \mathrm{ppm},-95$ to $-105 \mathrm{ppm}$ and -100 to $-110 \mathrm{ppm}$ that are observed, which respectively attributes to $\mathrm{Q}^{0} \mathrm{Si}(4 \mathrm{Al}), \mathrm{Q}^{1} \mathrm{Si}(3 \mathrm{Al}), \mathrm{Q}^{2} \mathrm{Si}(2 \mathrm{Al}), \mathrm{Q}^{3} \mathrm{Si}(1 \mathrm{Al})$ and $\mathrm{Q}^{4} \mathrm{Si}(0 \mathrm{Al})$ that describes all types of $-\mathrm{Si}-\mathrm{O}-\mathrm{Al}-\mathrm{O}-$ in the framework of zeolites [33]. In NaY-LDX, the highest intensity is shown by $\mathrm{Q}^{2}$ which indicates that the $\mathrm{SiO}_{4}{ }^{4-}$ surrounded by two $\mathrm{AlO}_{4}{ }^{5-}$ are the dominating species in NaY-LDX framework, while $\mathrm{Q}^{0}$ and $\mathrm{Q}^{4}$ species are the lowest intensity, while both in NaY-SW and commercial NaY, $\mathrm{Q}^{3}$ has the highest and $\mathrm{Q}^{1}, \mathrm{Q}^{4}$ have similar intensities.
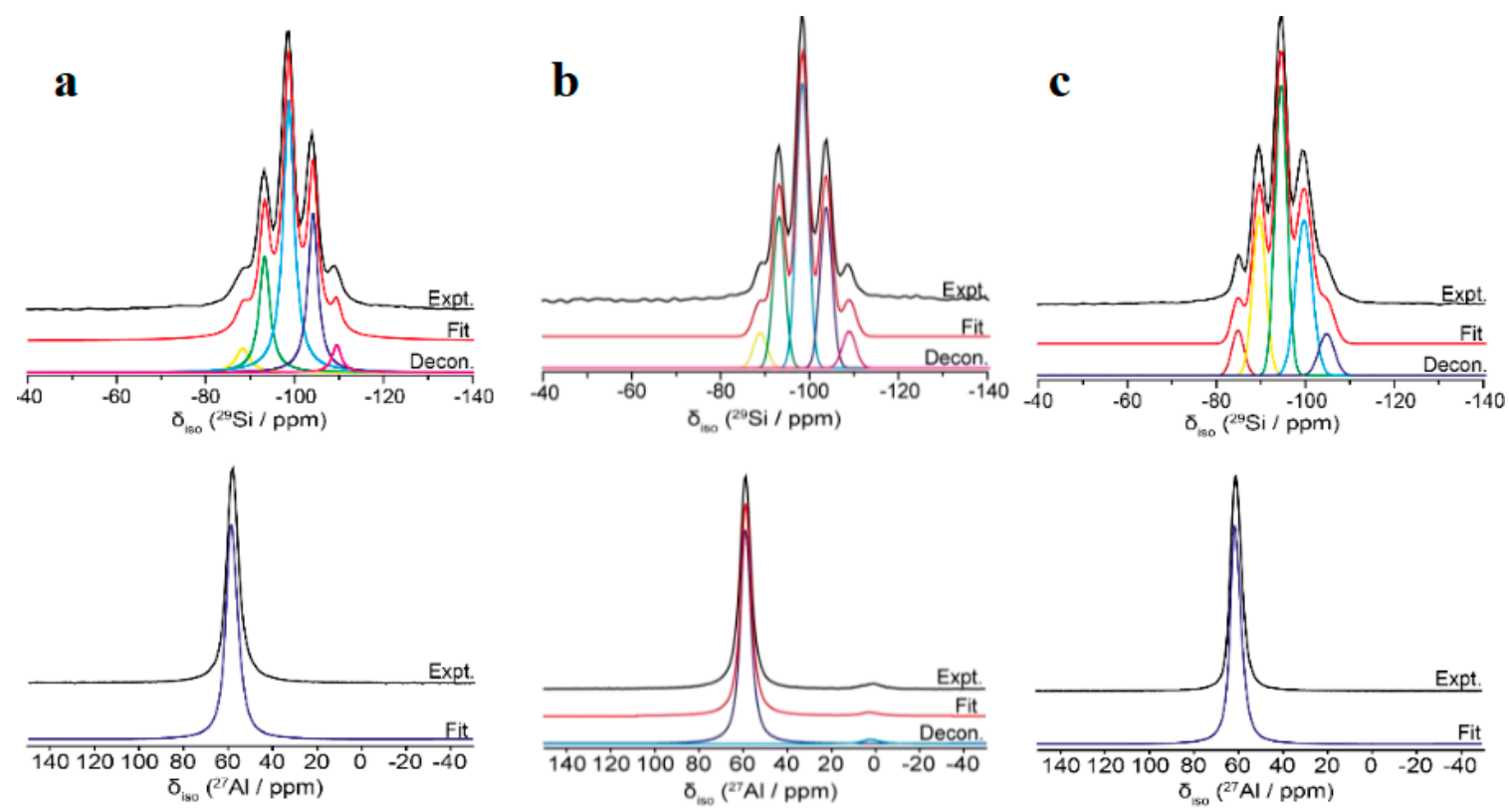

Figure 7. ${ }^{29}$ Si MAS NMR data (top) and ${ }^{27} \mathrm{Al}$ MAS NMR data (bottom) of (a) NaY-LDX; (b) NaY-SW and (c) commercial NaY.

The ${ }^{27} \mathrm{Al}$ NMR spectra of all NaY zeolites show strong peak with chemical shifts between 50 and $70 \mathrm{ppm}$ as an evidence of tetrahedral $\mathrm{Al}$ species in the framework [29]. However, a small peak at $0 \mathrm{ppm}$ chemical shift, attributed to octahedral Al species, was observed in NaY-SW spectrum. This indicates that NaY-SW contains not only framework-Al species but also $\mathrm{Al}$ on the surfaces so NaY-SW has poorer 
structure compared to NaY-LDX. The NMR data analysis supports the XRD result to use NaY-LDX as seed in NaY synthesis. So, in this research, NaY LDX was chosen as seed for the next NaY synthesis.

\subsection{Synthesis NaY Zeolite}

Two batches of NaY were synthesized using NaY-LDX as seed $5 \%(w / w)$ and silica sources from treated natural Belitung kaolin, i.e., extracted silica (labelled as NaY-SE) and extracted silica with metakaolin (named as NaY-MKSE). The characterization on the two as-synthesized materials are explained below.

SEM images in Figure 8 shows from NaY-LDX has a cuboid shape and sharp edges. Both of NaY-MKSE and NaY-SE also showed similar structure with NaY-LDX. However, the crystal habits of NaY-MKSE and NaY-SE are smaller and not as well-developed as those from NaY-LDX. This is due to defects that were caused by impurities from metakaolin or extracted silica.
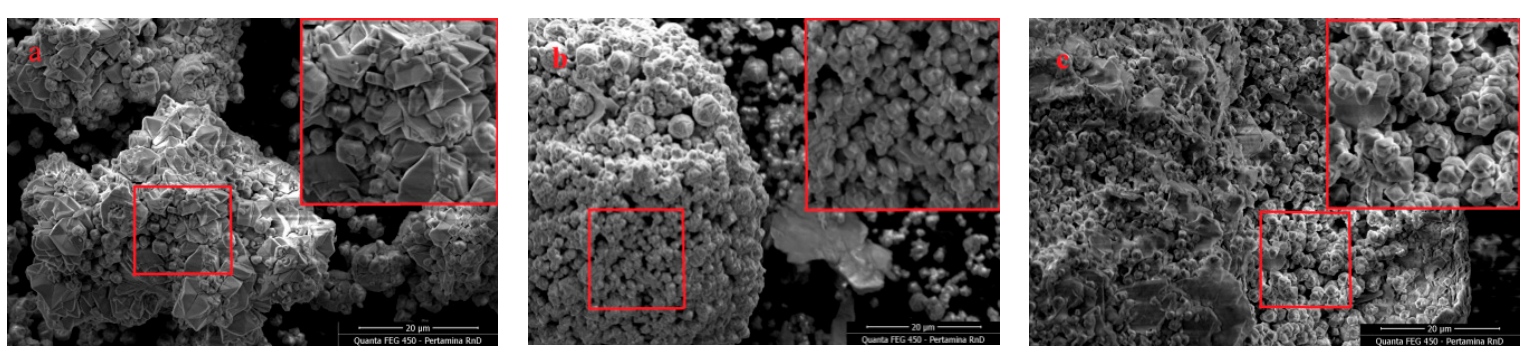

Figure 8. SEM images for (a) NaY-LDX, (b) NaY-MKSE and (c) NaY-SE. The insets show $\times 2$ magnification images.

Table 2 shows the chemical composition of NaY, measured with XRF. Overall, the $\mathrm{SiO}_{2} / \mathrm{Al}_{2} \mathrm{O}_{3}$ ratio of the three $\mathrm{NaY}$ zeolites are within the range of the $\mathrm{SiO}_{2} / \mathrm{Al}_{2} \mathrm{O}_{3}$ ratio for Y zeolite [9], in which the value was increased from NaY-LDX, NaY-MKSE to NaY-SE. The latter has the highest ratio due to the use of extracted silicate as silica source.

Table 2. Chemical composition of NaY zeolites.

\begin{tabular}{cccc}
\hline Chemical Composition & NaY-LDX Mass (\%) & NaY-MKSE Mass (\%) & NaY-SE Mass (\%) \\
\hline $\mathrm{Na}_{2} \mathbf{O}$ & - & 2.70 & 1.77 \\
$\mathrm{Al}_{\mathbf{2}} \mathbf{O}_{3}$ & 20.32 & 18.67 & 18.03 \\
$\mathrm{SiO}_{\mathbf{2}}$ & 75.86 & 72.62 & 74.15 \\
$\mathbf{P}_{\mathbf{2}} \mathbf{O}_{5}$ & 1.57 & 1.12 & 1.26 \\
$\mathrm{Cl}$ & 1.05 & 0.76 & 0.88 \\
$\mathrm{CaO}$ & 0.95 & 0.73 & 0.79 \\
$\mathbf{F e}_{2} \mathbf{O}_{3}$ & 0.26 & 2.80 & 2.38 \\
$\mathbf{S i O}_{2} / \mathbf{A l}_{\mathbf{2}} \mathbf{O}_{3}$ & $\mathbf{3 . 7 3}$ & $\mathbf{3 . 8 8}$ & $\mathbf{4 . 1 1}$ \\
\hline
\end{tabular}

As a supporting data, the measurement using FTIR was also performed. As seen in the Figure 9, the FTIR spectra of the NaY zeolite shows the bands in the range of $3560-3200 \mathrm{~cm}^{-1}$ are due to hydrogen-bonded silanol groups on the surface $(\sim \mathrm{Si}-\mathrm{OH})$ and bands in the region of $1140-450 \mathrm{~cm}^{-1}$ are due to the lattice $\mathrm{Si}-\mathrm{O}-\mathrm{Si}$ or $\mathrm{Si}-\mathrm{O}-\mathrm{Al}$ vibrations. 


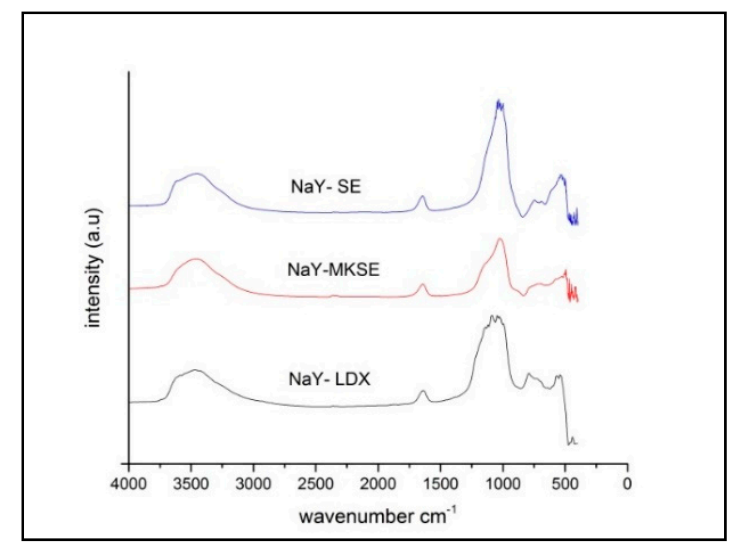

Figure 9. FTIR spectra of as-synthesized NaY zeolites from natural and synthetic precursor materials: NaY-SE (top), NaY-MKSE (middle) and NaY-LDX (bottom).

As seen, Figure 10 shows XRD Pattern for as-synthesized NaY that both NaY-SE and NaY-MKSE have all typical peaks of $\mathrm{NaY}$ zeolites and in agreement with the pattern from commercially available $\mathrm{NaY}$.

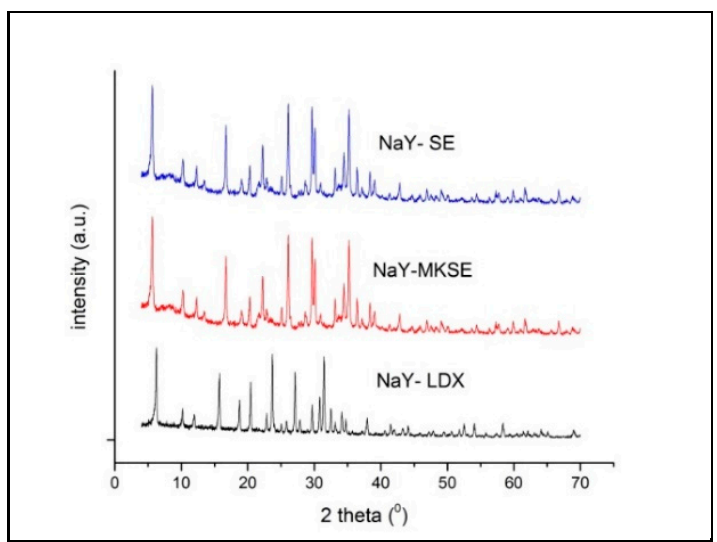

Figure 10. XRD data of as-synthesized $\mathrm{NaY}$ zeolites from natural and synthetic precursor materials: NaY-SE (top), NaY-MKSE (middle) and NaY-LDX (bottom).

Crystallinity of zeolite have been calculated by taking the sum total of relatives intensities of characteristic peaks $\left(2 \theta 6.2^{\circ} ; 15.6^{\circ} ; 22.1^{\circ}\right)$ following Equation (1). In this research, NaY-LDX is used as the standard.

$$
\text { Crystallinity Index }=\frac{\text { Sum Total of Relatives Intensities of NaY Observed }}{\text { Sum Total of Relatives Intensities of NaY Standard }} \times 100 \%
$$

Table 3 summarizes the degree of crystallinity of all as-synthesized zeolites. The calculation on NaY-SW shows that it has low crystallinity $(0.51 \%)$ while commercial $\mathrm{NaY}$ has the highest crystallinity $(45.00 \%)$. As for NaY-MKSE and NaY-SE, their degree of crystallinity is $18.22 \%$ and $35.80 \%$, respectively.

Surface area analyses were carried out on the three crystalline as-synthesized $\mathrm{NaY}$ zeolites and the results are shown in Figure 11 and Table 4. Figure 11a showing the adsorption-desorption isotherm from all zeolites confirms that all zeolites are microporous materials [22]. This is proofed further by Figure $11 \mathrm{~b}$ displaying that the distribution of pore radii $\left(\mathrm{r}_{\text {pore }}\right)$ lies at $1.14 \mathrm{~nm}$. Furthermore, the NaY-LDX has the highest surface, followed by NaY-MKSE and NaY-SE, respectively. 
Table 3. The XRD surface area peak analyses of various NaY preparations.

\begin{tabular}{ccc}
\hline Materials & Surface Area Peak ${ }^{*} \mathbf{2 \theta}\left(\mathbf{6 . 1}^{\circ} ; \mathbf{1 5 . 6}^{\circ} ; \mathbf{2 2 . 1}^{\circ}\right)$ & Crystallinity \\
\hline Commercial NaY & 376.88 & $45.00 \%$ \\
NaY-SW & 4.314 & $0.51 \%$ \\
NaY-LDX & 820.69 & $100.00 \%$ \\
NaY-MKSE & 149.41 & $18.22 \%$ \\
NaY-SE & 293.85 & $35.80 \%$ \\
\hline
\end{tabular}

* from XRD data.
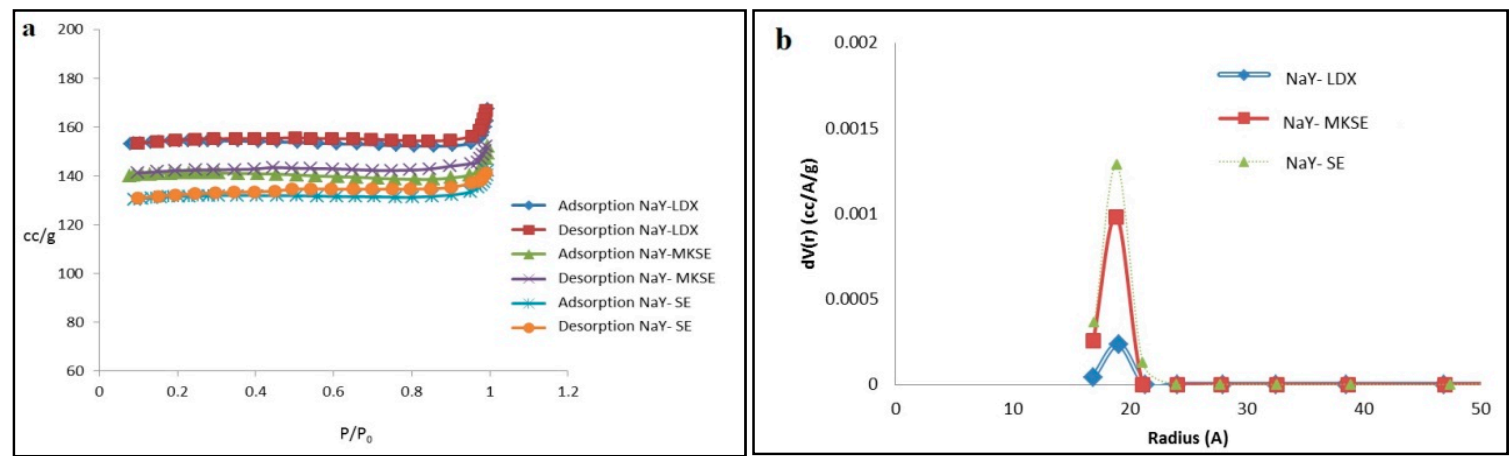

Figure 11. The (a) adsorption and desorption data and (b) pore distribution data of NaY.

Table 4. The surface area analysis results of the as-synthesized NaY preparations.

\begin{tabular}{|c|c|c|c|c|c|c|c|}
\hline \multirow[b]{2}{*}{ Materials } & \multicolumn{3}{|c|}{ Surface Area } & \multicolumn{3}{|c|}{ Pore Volume (V) } & \multirow{2}{*}{$\begin{array}{l}\mathbf{r}_{\text {pore }} \\
(\mathrm{nm})\end{array}$} \\
\hline & $\begin{array}{c}\mathrm{S}_{\mathrm{BET}} \\
\left(\mathrm{m}^{2} / \mathrm{g}\right)\end{array}$ & $\begin{array}{c}S_{\text {EXT }} \\
\left(\mathrm{m}^{2} / \mathrm{g}\right)\end{array}$ & $\begin{array}{l}S_{\text {mikro }} \\
\left(\mathrm{m}^{2} / \mathrm{g}\right)\end{array}$ & $\begin{array}{c}V_{\text {total }} \\
\left(\mathrm{cm}^{3} / \mathrm{g}\right)\end{array}$ & $\begin{array}{c}V_{\text {meso }} \\
\left(\mathrm{cm}^{3} / \mathrm{g}\right)\end{array}$ & $\begin{array}{l}V_{\text {mikro }} \\
\left(\mathrm{cm}^{3} / \mathrm{g}\right)\end{array}$ & \\
\hline NaY-LDX & 451.9 & 7.083 & 444.8 & 0.259 & 0.025 & 0.234 & 1.1468 \\
\hline NaY-MKSE & 412.7 & 5.810 & 406.9 & 0.235 & 0.021 & 0.214 & 1.1414 \\
\hline NaY-SE & 383.2 & 7.180 & 376.2 & 0.219 & 0.019 & 0.200 & 1.1463 \\
\hline
\end{tabular}

NMR analysis in Figure 12 shows the comparison of ${ }^{29} \mathrm{Si}$ and ${ }^{27} \mathrm{Al}$ NMR spectra of NaY-MKSE and $\mathrm{NaY}-\mathrm{SE}$. It can be seen that the dominant species in both as-synthesized $\mathrm{NaY}$ is $\mathrm{Q}^{3} \mathrm{Si}(1 \mathrm{Al})$, followed by equal amount of $\mathrm{Q}^{2} \mathrm{Si}(2 \mathrm{Al})$ and $\mathrm{Q}^{1} \mathrm{Si}(3 \mathrm{Al})$ species and weaker peak for $\mathrm{Q}^{0} \mathrm{Si}(4 \mathrm{Al})$ at -80 to -90 ppm. Interestingly, only a shoulder peak was observed at -100 to $-110 \mathrm{ppm}$, assigned for $\mathrm{Q}^{4} \mathrm{Si}$ (0Al). No peaks were observed in CP MAS Si NMR, indicating no significant amount of $\sim \mathrm{Si}-\mathrm{OH}$ exist on the surface of the zeolites.

The ${ }^{27} \mathrm{Al}$ NMR spectra of the as-synthesized NaY zeolites show a strong peak with chemical shifts between 50 and 70 ppm as an evidence of tetrahedral Al species in the framework [29]. However, a small peak at 0 ppm chemical shift, attributed to octahedral Al species, was also observed, indicating that the zeolites have defective Al species to form an extended-framework on the surfaces. 

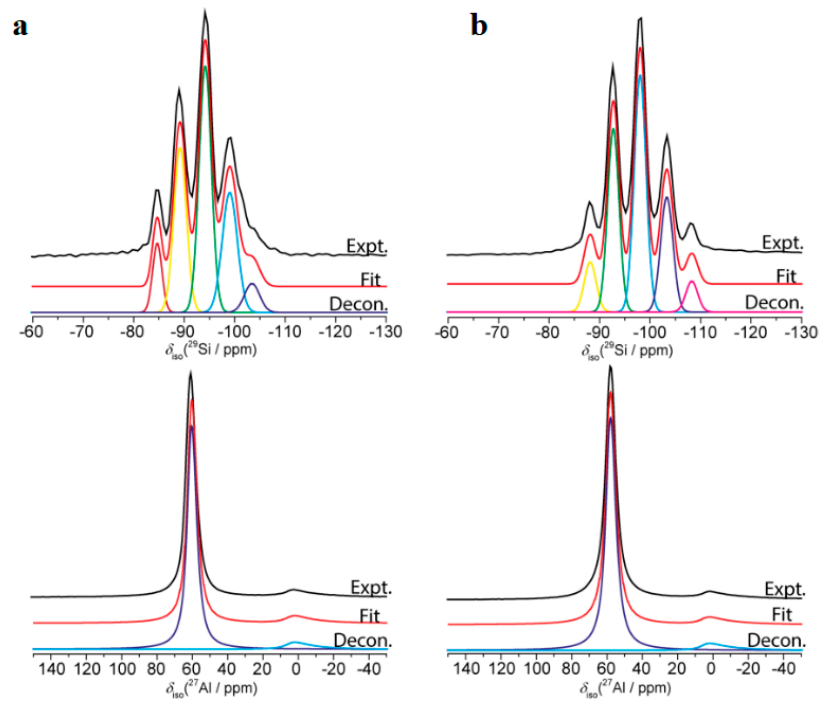

Figure 12. ${ }^{29} \mathrm{Si}$ (top) and ${ }^{27} \mathrm{Al}$ (bottom) MAS NMR data of: (a) NaY-MKSE and (b) NaY-SE.

\subsection{Preparation of HY Zeolites as Cracking Catalysts}

In general, cracking reaction of long chain alkane requires Brønsted acid catalyst, in which zeolite can be used as so that heterogeneous acid catalyst as the silanol groups $(-\mathrm{SiOH})$ play a role as acidic sites, providing $\mathrm{H}^{+}$ions [34]. NaY zeolites were exchanged to $\mathrm{NH}_{4} \mathrm{Y}$ then calcined to remove $\mathrm{NH}_{3}$ and providing mobile $\mathrm{H}^{+}$balancing the charge in the framework of zeolite. The $\mathrm{H}$-type zeolites were labeled as HY-LDX, HY-MKSE, HY-SE, respectively.

Figure 13 shows XRD pattern of $\mathrm{HY}$ zeolites which very much resemble their parent $\mathrm{NaY}$ zeolites, while the $\mathrm{SiO}_{2} / \mathrm{Al}_{2} \mathrm{O}_{3}$ ratio (for brevity, the XRF results are not shown) of each zeolite stays in the same range of NaY zeolites (3.53-3.98). Thus, it can be concluded that the structure of $Y$ zeolites is not damaged during preparation of HY zeolites.

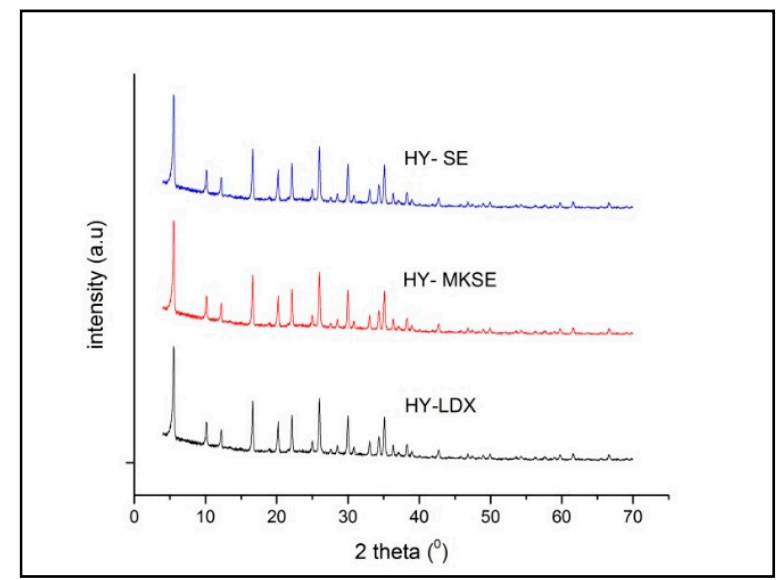

Figure 13. XRD data of HY- LDX (bottom), HY-MKSE (middle) and HY-SE (top).

\section{5. n-Hexadecane Catalytic Cracking}

The modified HY zeolites are tested as catalysts in the cracking reaction using $n$-hexadecane as the model compound. The catalytic activities were analyzed from the percentage conversion $(\% \mathrm{X})$, yield $(\% \mathrm{Y})$ and selectivity $(\% \mathrm{Y})$ toward $\mathrm{C}_{5}-\mathrm{C}_{12}$ compounds representing gasoline that is described in Figures 14 and 15 . Figure 14 shows that the highest catalytic activity in $n$-hexadecane cracking reaction is given by HY-LDX, followed by HY-SE and HY-MKSE. 


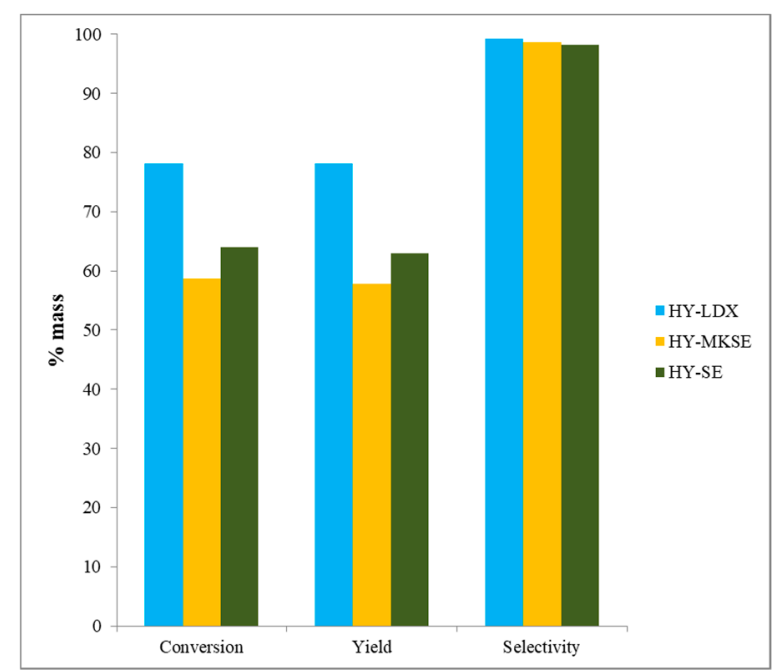

Figure 14. A comparison of percent conversion, yield and selectivity from zeolite HY.

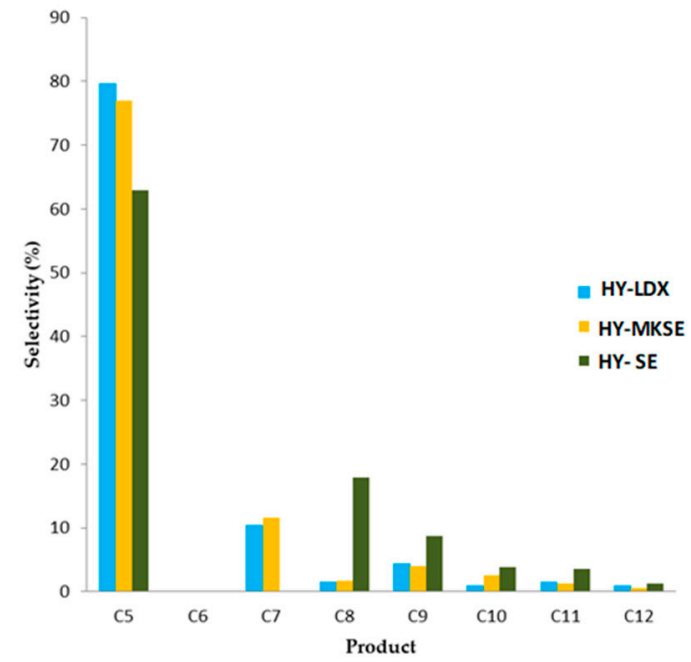

Figure 15. A comparison of the percent selectivity on gasoline products.

Figure 15 compares the selectivity to each gasoline product $\left(\mathrm{C}_{5}-\mathrm{C}_{12}\right)$ when using the three catalysts. It can be seen that the product with the highest percentage of selectivity is $C_{5}$ compound (n-pentane and iso-pentane). Interestingly, HY-SE is also selective to $\mathrm{C}_{8}$ (n-octane and iso-octane) while other HY catalysts are less selective.

\section{Discussion}

The results presented above shows that the transformation from layered structure kaolin to three-dimensional NaY zeolites is successfully performed. Pre-treatment procedure, in which the kaolin structure was fragmented to become metakaolin as well as the extraction of silica becomes an important step to prepare adequate silicate and aluminate precursors for the next step, building the NaY framework. The characterization on the starting materials, the kaolin-based precursors as well as the as-synthesized $\mathrm{NaY}$ have been able to prove almost the entire steps. The crystallinity and physical-chemical properties of kaolin based-NaY are also comparable to that of pro analysis-NaY. As an implication, their catalytic activity as cracking catalyst, in HY-form, are also comparable compared to the pristine pro analysis-NaY. This finding could be taken into account when alternative sources of precursors for materials synthesis that meet the green chemistry concept yet affordable, are required. Further study has to be carried out to improve the pre-treatment techniques to obtain much smaller fragment of silicate and aluminate from kaolin also with higher purity. 


\section{Conclusions}

It can be concluded that transformation from layer structured kaolin to tectosilicate structure of $\mathrm{NaY}$ was successful. Kaolin can be utilized as aluminate and silicate sources through metakaolinization and silica extraction process. The presence of crystalline NaY seeds is important in NaY zeolite synthesis using either synthetic or natural precursor. Furthermore, the kaolin-based HY has shown high performance as an active catalyst in the cracking reaction of $n$-hexadecane.

Author Contributions: Conceptualization, Y.K.K., R.S.; formal analysis, Y.K.K., I.R.S., I.P.S., B.E.G. and J.V.H.; funding acquisition, Y.K.K.; investigation, I.R.S., I.P.S., B.E.G., R.E.; methodology, Y.K.K., R.S., R.E. and J.V.H.; project administration, Y.K.K.; supervision, Y.K.K. and R.S.; Writing-Original Draft, Y.K.K., I.R.S. and I.P.S.; Writing-Review and Editing, Y.K.K., I.R.S., R.S., I.P.S. and J.V.H.

Funding: This work and APC were funded by PUPT BPPTN 2019 grant No. NKB-1720/UN2.R3.1/HKP.05.00/2019 from Indonesian Ministry of Research and Higher Education. Cracking catalytic test was funded by Collaboration Research Project PT. Pertamina-Universitas Indonesia No. 004/E20400/2016-S0.

Acknowledgments: JVH thanks the EPSRC, the University of Warwick and the Birmingham Science City Program for partial funding of the solid-state NMR infrastructure at Warwick. The latter program accessed the Birmingham Science City Advanced Materials Project 1: Creating and Characterizing Next Generation Advanced Materials, which derived support from Advantage West Midlands (AWM) and the European Regional Development Fund (ERDF). YKK thanks Sung-Min Choi at KAIST and Aminah Umar at UI for access to SEM measurements.

Conflicts of Interest: The authors declare no conflict of interest. The sponsors had no role in the design, execution, interpretation, or writing of the study.

\section{References}

1. Dionisiou, N.S.; Matsi, T. Natural and Surfactant-Modified Zeolite for the Removal of Pollutants (Mainly Inorganic) from Natural Waters and Wastewaters; Elsevier Inc.: Amsterdam, The Netherlands, 2016.

2. Panias, D.; Xenidis, A.; Krestou, A. Materials and Processes for Uranium Removal from Contaminated Water; Elsevier Masson SAS: Paris, France, 2007; Volume 7.

3. Swenson, P.; Tanchuk, B.; Bastida, E.; An, W.; Kuznicki, S.M. Water desalination and de-oiling with natural zeolite membranes-Potential application for purification of SAGD process water. Desalination 2012, 286, 442-446. [CrossRef]

4. Coal, R.; Bay, R.; Adriatic, N. Use of Bacteria and Synthetic Zeolites in Remediation of Soil and Water Polluted with Superhigh-Organic-Sulfur. Water 2019, 11, 1419.

5. Calabrese, L.; Proverbio, E. A Brief Overview on the Anticorrosion Performances of Sol-Gel Zeolite Coatings. Coatings 2019, 9, 409. [CrossRef]

6. Davis, M. Ordered Porous Materials for Emerging Applications. Nature 2015, 10, 924-936. [CrossRef] [PubMed]

7. Primo, A.; Garcia, H. Zeolites as catalysts in oil refining. Chem. Soc. Rev. 2014, 43, 7548-7561. [CrossRef] [PubMed]

8. Johnson, E.B.G.; Arshad, S.E. Hydrothermally synthesized zeolites based on kaolinite: A review. Appl. Clay Sci. 2014, 97-98, 215-221. [CrossRef]

9. Lutz, W. Zeolite Y: Synthesis, Modification, and Properties-A Case Revisited. Adv. Mater. Sci. Eng. 2014, 2014, 724248. [CrossRef]

10. Meng, X.; Xiao, F. Green Routes for Synthesis of Zeolites. Chem. Rev. 2014, 114, 1521-1543. [CrossRef]

11. Adamczyk, Z. Hydrothermal Synthesis of Zeolites from Polish Coal Fly Ash. Pol. J. Environ. Stud. 2005, 14, 713-719.

12. Margenot, A.J.; Parikh, S.J. IR Spectroscopy in Soil Analysis Applications; Elsevier Inc.: Amsterdam, The Netherlands, 2016; pp. 913-928.

13. Lazzara, G.; Cavallaro, G.; Panchal, A.; Fakhrullin, R.; Stavitskaya, A.; Vinokurov, V.; Lvov, Y. An assembly of organic-inorganic composites using halloysite clay nanotubes. Curr. Opin. Colloid Interface Sci. 2018, 35, 42-50. [CrossRef]

14. Sadjadi, S.; Lazzara, G.; Malmir, M.; Heravi, M.M. Pd nanoparticles immobilized on the poly-dopamine decorated halloysite nanotubes hybridized with $\mathrm{N}$-doped porous carbon monolayer: A versatile catalyst for promoting Pd catalyzed reactions. J. Catal. 2018, 366, 245-257. [CrossRef] 
15. Massaro, M.; Colletti, C.G.; Lazzara, G.; Milioto, S.; Notoa, R.; Riela, S. Halloysite nanotubes as support for metal-based catalysts. J. Mater. Chem. 2017, 5, 13276-13293. [CrossRef]

16. Krisnandi, Y.K.; Parmanti, I.Y.; Yunarti, R.T.; Sihombing, R.; Saragi, I.R. Synthesis and Characterization of Zeolite NaY from kaolin Bangka Belitung with variation of synthesis composition and crystallization time. J. Phys. Conf. Ser. 2018, 1095, 012043. [CrossRef]

17. Melaningtyas, G.S.A.; Krisnandi, Y.K.; Ekananda, R. Synthesis and characterization of NaY zeolite from Bayat natural zeolite: Effect of pH on synthesis. IOP Conf. Ser. Mater. Sci. Eng. 2019, 496, 012042. [CrossRef]

18. Zahara, Z.; Krisnandi, Y.K.; Wibowo, W.; Nurani, D.A.; Rahayu, D.U.C.; Haerudin, H. Synthesis and characterization of hierarchical ZSM-5 zeolite using various templates as cracking catalysts. AIP Conf. Proc. 2018, 2023, 020088.

19. Saragi, I.R.; Krisnandi, Y.K.; Sihombing, R. Synthesis and Characterization HY Zeolite from Natural Aluminosilicate for $n$-Hexadecane Cracking. Mater. Today Proc. 2019, 13, 76-81. [CrossRef]

20. Ming, D.W.; Dixon, J.B. Technique for the Separation of Clinoptilolite from Soils. Clays Clay Miner. 1987, 35, 4-7. [CrossRef]

21. Gougazeh, M.; Buhl, J.C. Synthesis and characterization of zeolite A by hydrothermal transformation of natural Jordanian kaolin. J. Assoc. Arab Univ. Basic Appl. Sci. 2014, 15, 35-42. [CrossRef]

22. Liu, Z.; Shi, C.; Wu, D.; He, S.; Ren, B. A Simple Method of Preparation of High Silica Zeolite y and Its Performance in the Catalytic Cracking of Cumene. J. Nanotechnol. 2016, 2016, 1486107. [CrossRef]

23. Ginter, D.M.; Bell, A.T.; Radke, C.J. The effects of gel aging on the synthesis of NaY zeolite from colloidal silica. Zeolites 1992, 12, 742-749. [CrossRef]

24. Harris, R.K.; Becker, E.D.; de Menezes, S.M.C.; Goodfellow, R.; Granger, P. NMR Nomenclature: Nuclear Spin Properties and Conventions for Chemical Shifts. Solid State Nucl. Magn. Reson. 2002, 22, 458-483. [CrossRef]

25. Feng, H.; Li, C.; Shan, H. Effect of Calcination Temperature of Kaolin Microspheres on the In situ Synthesis of ZSM-5. Catal. Lett. 2009, 129, 71-78. [CrossRef]

26. Stylianou, M.; Inglezakis, V.; Agapiou, A.; Itskos, G.; Jetybayeva, A.; Loizidou, M. A comparative study on phyllosilicate and tectosillicate mineral structural properties. Desalin. Water Treat. 2018, 112, 119-146. [CrossRef]

27. Rohayati, Y.; Krisnandi, K.; Sihombing, R. Synthesis of ZSM-5 zeolite using Bayat natural zeolite as silica and alumina source. AIP Conf. Proc. 2017, 1862, 1-5.

28. Abdullahi, T.; Harun, Z.; Othman, M.H.D. A review on sustainable synthesis of zeolite from kaolinite resources via hydrothermal process. Adv. Powder Technol. 2017, 28, 1827-1840. [CrossRef]

29. Stepanov, A.G. Basics of Solid-State NMR for Application in Zeolite Science; Elsevier B.V.: Amsterdam, The Netherlands, May 2016.

30. Li, S.; Deng, F. Recent Advances of Solid-State NMR Studies on Zeolites, 1st ed.; Elsevier Ltd.: Amsterdam, The Netherlands, 2013; Volume 78.

31. Abbas, A.S.; Abbas, R.N. Preparation and Characterization of Nay Zeolite for Biodiesel Production. Iraqi J. Chem. Pet. Eng. 2015, 16, 19-29.

32. Foster, M.D.; Rivin, I.; Treacy, M.M.J.; Friedrichs, O.D. A geometric solution to the largest-free-sphere problem in zeolite frameworks. Microporous Mesoporous Mater. 2006, 90, 32-38. [CrossRef]

33. Gore, K.U.; Abraham, A.; Hegde, S.G.; Kumar, R.; Amoureux, J.; Ganapathy, S. 29SiMAS and 27Al/3Q-MAS NMR Studies of High Silica USY Zeolites. J. Phys. Chem. B 2002, 106, 6115-6120. [CrossRef]

34. Weitkamp, J. Zeolites and catalysis. Solid State Ion. 2000, 131, 175-188. [CrossRef]

(C) 2019 by the authors. Licensee MDPI, Basel, Switzerland. This article is an open access article distributed under the terms and conditions of the Creative Commons Attribution (CC BY) license (http://creativecommons.org/licenses/by/4.0/). 